\title{
Graphene - Polyaniline Nanocomposite Treated with Microwave as a New Supercapaci- tor Electrode and its Structural, Electrochemical Properties
}

\author{
Senthil Kumar Kandasamy ${ }^{1}$ and Kannan Kandasamy ${ }^{2, *}$ \\ ${ }^{1}$ Department of Electronics and Communication Engineering, Kongu Engineering College, Perundurai, Tamil Nadu INDIA \\ ${ }^{2}$ Department of Chemical Engineering, Kongu Engineering College, Perundurai, Tamil Nadu INDIA
}

Corresponding Author Email: kannank@kongu.ac.in

\begin{abstract}
The graphene/polyaniline novel composites have been synthesized through modified hummers' method and in situ polymerization and treated the composite with microwave irradiation. The composites with various weight feed ratio of polyaniline (PANI) to graphene are synthesized and duration for microwave treatment has been optimized. Then the composites have been characterized by Fourier Transform Infrared Spectroscopy (FTIR), Raman spectroscopy, Cyclic Voltammetry (CV), Galvanostatic Charge and Discharge (GCD) measurements and Electrochemical Impedance Spectroscopy (EIS). The electrochemical tests show that the electrochemical performances of microwave treated graphene/PANI depend largely on the mass ratios of PANI to graphene and the microwave treatment. Compared with the electrode materials, the composite (MPG21) has the highest specific capacitance of $249.32 \mathrm{Fg}^{-1}$ at a scan rate of $10 \mathrm{mVs} \mathrm{s}^{-1}$ and good charge and discharge cycling stability. The improved electrochemical performances of microwave treated graphene/PANI are ascribed to the synergistic effects between the PANI and graphene. The excellent electrochemical performance of the composite electrode suggests of promising application for high performance supercapacitor.
\end{abstract}

Keywords: Graphene, Polyaniline, Supercapacitor, Microwave treatment

Received: April-30-2018, Accepted: December-20-2018, https://doi.org/10.14447/jnmes.v22i3.a02

\section{INTRODUCTION}

Development of sustainable and renewable energy devices has gained more demand due to the growing global energy consumption along with depletioning of fossil fuel. Supercapacitor is a novel energy storage device that fills the gap between capacitors and batteries. It has attracted more researchers due to its power density and cyclic life. Supercapacitors are classified into two broad categories based on the energy storage mechanism namely Electric Double Layer Capacitor (EDLC), which is non-faradaic process and pseudocapacitor. The important factors affecting the performance of supercapacitors are the electrode materials and electrolyte [1]. The researches about supercapacitor mainly concentrate on the electrode materials such as carbon materials, metal oxides and conducting polymers. Other than CNT and carbon nanofiber, graphene and its composite materials have been studied as electrode materials. Graphene based materials possesses better electrochemical property than CNT.

Direct application of pseudocapacitors in supercapacitor is restricted due to the lower cycle life. Among the different conducting polymers, polyaniline (PANI) is most promising candidate for its low cost, easy synthesis and adjustable electrical conductivity. Polyaniline has been used to fabricate composites with graphene for supercapacitor electrodes due to its environmental stability. This makes the combination of carbon materials and conducting polymers, which lead to the improvement in electrochemical supercapacitor. Graphene oxide $/ \mathrm{MnO}_{2}$ [2-3], Graphene $/ \mathrm{Fe}_{2} \mathrm{O}_{3}$ [4], Graphene/Polypyrrole [5-7], Graphene/CNT in Polypyrrole [8] and Graphene/Polyaniline [9-11] were the major electrode material used by researcher in supercapacitor. Graphene possesses many remarkable properties such as high surface area, electrical conductivity, large double layer capacitance and excellent mechanical strength. Existence of pseudocapacitance generated from the oxygen containing groups makes graphene oxide is more suitable for supercapacitor application than graphene. Sulfonated graphene is used as a dopant in conducting polymers, due to demerits such as easy agglomeration and stacking of graphene sheets [12].

Graphene/polypyrrole composites have been successfully fabricated and exhibited a specific capacitance as high as $318.6 \mathrm{Fg}^{-1}$ at a scan rate of $2 \mathrm{mVs}^{-1}$ [5]. Graphene oxide - wrapped polyaniline hollow microsphere has been synthesized through a self assembly method and exhibited a specific capacitance value of $731.2 \mathrm{Fg}^{-1}$ at a scan rate of 5 $\mathrm{mVs}^{-1}$ [9]. The excellent electrochemical performance of graphene / polyaniline composite leads to the high performance supercapacitor. $\mathrm{pH}$ value plays an important role in controlling the electrochemical properties of an electrode [13]. At $5 \mathrm{mVs}^{-1}$, the energy and power density of polypyrrole - graphene - CNT electrode was $62.96 \mathrm{~W} \mathrm{~h} \mathrm{~kg}^{-1}$ and $566.66 \mathrm{~W} \mathrm{~kg}^{-1}$, respectively [8]. Ternary composites of $\mathrm{MnO}_{2} /$ Polyaniline/Graphene oxide have been prepared and showed the specific capacitance of $712 \mathrm{Fg}^{-1}$ with $\sim 97 \%$ capacitance retained even after 5000 cycles [14]. The obtained specific capacitance of Poly (anthraquinonyl sulfide) / graphene sheet was $349 \mathrm{Fg}^{-1}$ at $500 \mathrm{mAg}^{-1}$ [15]. The graphene/polyaniline composite's water content is one of the important factors which influenced the electrochemical performance of the composite.

Due to the large number of active sites which are responsible for the charge transfer and ion transport through the electrode and good electrical conductivity of graphene nanosheets, specific capacitance of polyaniline/graphene nanosheet was $528 \mathrm{Fg}^{-1}$ at $10 \mathrm{mVs}^{-1}$ [16]. Mazhar B.Tayal et al. [17] fabricated a supercapacitor using an electrode made up of graphene layer covered by polyaniline layer using spraying technique, which exhibited a maximum specific capacitance of $915.78 \mathrm{Fg}^{-1}$ at $5 \mathrm{mVs}^{-1}$. Hualan wang et al. [18] synthesized a new good performance electrode based on fibrillar polyaniline doped with graphene 
oxide sheets via in situ polymerization of monomer and it showed the specific capacitance of $531 \mathrm{Fg}^{-1}$ in the potential range from 0 to $0.45 \mathrm{~V}$.

The supercapacitor made up of graphene/polypyrrole exhibited the specific capacitance of $270 \mathrm{Fg}^{-1}$ at $0.1 \mathrm{~Hz}$ [7]. At $5 \mathrm{mVs}^{-1}$, the specific capacitance of PCG electrode film was $453 \mathrm{Fg}^{-1}$ with energy density of $62.96 \mathrm{Wh} \mathrm{Kg}^{-1}$ and power density of $566.66 \mathrm{~W} \mathrm{Kg}^{-1}$ [8]. Supercapacitor devices based on self assembled graphene@PANI nanoworm composites showed the highest specific capacitance of $488.2 \mathrm{Fg}^{-1}$ at a discharge rate of $0.5 \mathrm{Ag}^{-1}$ [19]. Polyaniline grafted reduced graphene oxide composite was synthesized and showed the highest specific capacitance of $1337 \mathrm{Fg}^{-1}$ at $15 \mathrm{Ag}^{-1}$ [20]. Graphene / conducting polymer composite and graphene/carbon nanotube composite have displayed an impressive energy and power density [21].The layered polyaniline / graphene composite film exhibited $384 \mathrm{Fg}^{-1}$ at $0.5 \mathrm{Ag}^{-1}$ [22]. The low content of PANI in the PANI/ graphene nanosheets composite exhibited a remarkable specific capacitance of $261.4 \mathrm{Fg}^{-1}$ [23]. Flexible supercapacitor [24] was fabricated by a novel printing technique and subsequent $\mathrm{CO}_{2}$ bubbling delamination method. [3] reported a method to prepare graphene $/ \mathrm{MnO}_{2}$ composites as electrode materials by microwave irradiation. Supercapacitor can be used for various high power applications [25].

In this work, the graphene/polyaniline novel composites have been synthesized through modified hummers' method and in situ polymerization and the composite were treated with microwave irradiation, serving as an electrode material for supercapacitor. The combination of polyaniline and graphene improve the electrochemical performance and the microwave treated composite provide more active sites. The porous structure of microwave treated composite is expected to provide channels for rapid transport of ions and also enhance the diffusion of electrolyte into the electrodes. The as prepared composite and microwave treated composite were characterized by Fourier Transform Infrared Spectroscopy (FTIR), raman spectroscopy, Cyclic Voltammetry (CV), Galvanostatic Charge and Discharge (GCD) measurement and Electrochemical Impedance Spectroscopy (EIS). The chemical structure and electrochemical performance of the composite and microwave treated composite have been investigated. The work will focus on the microwave treated composite and its electrochemical performance. Undoubtedly, the microwave treated composite can improve the specific capacitance, energy density and power density of supercapacitor.

\section{EXPERIMENTAL SECTION}

\subsection{Materials}

Graphite powder was obtained from Aksharchem, sodium nitrate and potassium permanganate were from Merck, hydrogen peroxide and hydrochloric acid were purchased from Nice chemicals private limited and concentrated sulphuric acid was obtained from RFCL limited. All the materials were used as received without further purification.

\subsection{Synthesis of Graphene Oxide}

Graphene oxide (GO) was synthesized from natural graphite powder through the modified Hummers' method. $20 \mathrm{~g}$ of graphite and $5 \mathrm{~g}$ of sodium nitrate were mixed together followed by the addition of $230 \mathrm{ml}$ of conc. sulphuric acid under constant stirring. After $1 \mathrm{~h}, 15 \mathrm{~g}$ of $\mathrm{KMnO}_{4}$ was added gradually to the above solution while keeping the temperature less than $5^{\circ} \mathrm{C}$ to prevent overheating and explosion. The mixture was stirred at $6{ }^{\circ} \mathrm{C}$ for $14 \mathrm{~h}$ and the resulting solution was diluted by adding $250 \mathrm{ml}$ of water under vigorous stirring. To ensure the completion of reaction with $\mathrm{KMnO}_{4}$, the suspension was further treated with $30 \mathrm{~mL}$ of $\mathrm{H}_{2} \mathrm{O}_{2}$ solution. The resulting mixture was repeatedly washed with diluted $\mathrm{HCl}$, ethanol and DI water respectively, followed by filtration and dried in hot air oven at $100^{\circ} \mathrm{C}$ for $24 \mathrm{~h}$ and the desired graphene oxide sheets were thus obtained.

\subsection{Synthesis of PANI - GO nanocomposites}

PANI - GO nanocomposites were synthesized through an in-situ polymerization of aniline monomer in the presence of graphene oxide sheets. The mass ratio of aniline to graphene oxide is varied as 3:0.9, 3:1.5, 3:2.1 and 3:2.7 and labeled as PG09, PG15, PG21 and PG27, respectively. In a typical experiment, $0.9 \mathrm{~g}$ of graphene oxide was dispersed into $200 \mathrm{~mL}$ of distilled water and sonicated for 30 minutes. Then $3 \mathrm{ml}$ of aniline was taken and mixed with the above solution and sonicated for 20 minutes. $1 \mathrm{~g}$ of Ammonium persulphate was mixed with $80 \mathrm{~mL}$ of $1 \mathrm{M}$ concentrated sulphuric acid and kept in a stirrer for 5-7 minutes. Then the solution is added to the above solution and it is again kept in a stirrer for 4 hours. Finally, the product was collected and repeatedly washed with diluted $\mathrm{HCl}$, ethanol and DI water, then dried in hot air oven at $80^{\circ} \mathrm{C}$ for $24 \mathrm{~h}$.

\subsection{Microwave treatment of PANI-GO nanocompo- sites}

PANI-GO nanocomposites were treated in a microwave oven ( LG/MH3948WB ). The microwave oven had a maximum power of 640 Watts with 4 different power values such as 160, 320, 480 and 640W. The different graphene polymer nanocomposites were placed in a petri dish, which was kept in oven. After microwave irradiation, volume expansion of the composite observed at $320 \mathrm{~W}$ for 10 seconds only. Finally, the composites were treated in microwave oven, named as MPG09, MPG15, MPG21, and MPG27.

\section{MATERIAL CHARACTERIZATION METHODS}

Fourier transform infrared spectroscopy measurements of graphene/polyaniline nanocomposite and microwave treated graphene/polyaniline nanocomposite were measured by the $\mathrm{KBr}$ method recorded on Shimadzu spectrometer over a range from 400 to $4000 \mathrm{~cm}^{-}$ ${ }^{1}$. Raman spectroscopy is an effective analytical method to identify the structure and defects in composite materials [26]. Raman spectra were recorded on EZRaman-N analyzer employing $532 \mathrm{~nm}$ frequency stabilized, narrow line width diode Laser beam. In the electrochemical test, the active electrode was assembled into a three electrode system. The following steps are used for the preparation of the working electrode. To evaluate electrochemical performance in an aqueous solution, an electrode material was prepared using the active material, mixed with the rubber solution in the weight ratio $(60: 40)$. The mixture was prepared as slurry and coated on graphite rod with the help of brush. The pasted graphite lead electrodes were dried at room temperature for 30 minutes. The loading amount of active material is approximately 200 $\mu \mathrm{g}$. The electrolyte used was $0.5 \mathrm{M} \mathrm{H}_{2} \mathrm{SO}_{4}$ aqueous solution. The electrochemical behavior was characterized within a maximum potential window of -1.5 to $2 \mathrm{~V}$ vs. $\mathrm{Ag} / \mathrm{AgCl}$ reference electrode. Platinum wire was used as a counter electrode. The cyclic voltammetry measurements, galvanostatic charge and discharge measurements and electrochemical impedance spectroscopy were carried out on an electrochemical workstation ( metrohm, Netherlands, potentiostat - galvanostat).

\subsection{FTIR measurement}

The presence of surface functional groups can be identified by Fourier transform infrared spectroscopy. Fig. 1 (a) shows FTIR spectra of graphene/polyaniline composites (PG09, PG15, PG21, and PG27) and Fig. 1 (b) shows FTIR spectra of microwave treated graphene/polyaniline composites (MPG09, MPG15, MPG21, and MPG27) in the range of $400-4000 \mathrm{~cm}^{-1}$. The FTIR spectrum of the graphene/polyaniline composites and microwave treated graphene/polyaniline composites shows a mild peak at $3711 \mathrm{~cm}^{-1}$, representing an electrochemical reduction of GO during the polymerization [27]. A peak was appeared at $770 \mathrm{~cm}^{-1}$ is $\mathrm{N}-\mathrm{H}$ vibration of secondary amine group [20]. The absorption peaks at $1199 \mathrm{~cm}^{-1}$ of GO/PANI 

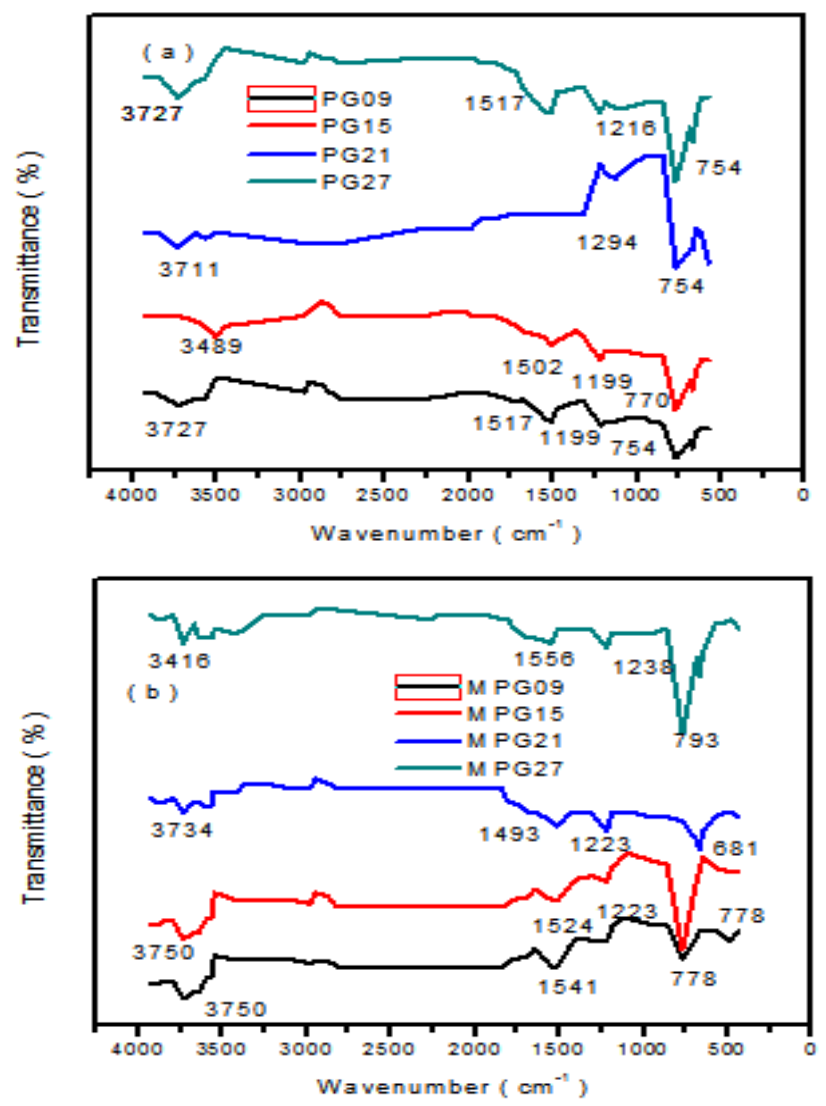

Fig. 1. Fourier transform infrared spectra of ( a ) graphene/polyaniline composite and ( $b$ ) microwave treated graphene/polyaniline composite

composite and $1223 \mathrm{~cm}^{-1}$ of microwave treated graphene/polyaniline composite are attributed to the $\mathrm{C}-\mathrm{N}$ stretching band of an aromatic amine [27]. The characteristic band at $1502 \mathrm{~cm}^{-1}$ ascribed to $\mathrm{C}=\mathrm{C}$ stretching vibration mode of benzenoid ring [28]. The spectra of microwave treated graphene/polyaniline composites are similar to the graphene/polyaniline composites. When compared to graphene/polyaniline composites, the peak appear at $1541 \mathrm{~cm}^{-1}$ corresponds to $\mathrm{C}=\mathrm{C}$ stretching of quinoid [28-30]. There is a type of interaction between graphene and polyaniline, which plays an important role in enhancing the electrochemical performance of both normal and microwave treated composite, by improving the mechanical stability of composite [28].

\subsection{Raman Spectroscopy}

Raman spectroscopy is used to study the interaction between graphene and polyaniline in the graphene/polyaniline nanocomposite and microwave treated graphene/polyaniline nanocomposite. The raman spectra of the PG09, PG15, PG21, PG27, MPG09, MPG15, MPG21, and MPG27 were given in Fig. 2 (a) and (b). The peaks at $1350 \mathrm{~cm}^{-1}$ and $1595 \mathrm{~cm}^{-1}$ can be attributed to D band and $\mathrm{G}$ band of graphene oxide, respectively. For the raman spectra of sample PG09, the band at $410 \mathrm{~cm}^{-1}$ is ascribed to out of plane amine ring deformations [31] and the band at $585 \mathrm{~cm}^{-1}$ is a confirmation of the existence of ring deformation. The band at about $873 \mathrm{~cm}^{-1}$ is in agreement with in plane ring deformation [32]. In sample PG21, the peak occurred at about $1171 \mathrm{~cm}^{-}$ ${ }^{1}$ corresponds to $\mathrm{C}-\mathrm{H}$ bending in the quinoid type rings. $\mathrm{C}-\mathrm{H}$ bending vibrations of benzene rings are observed at $1263 \mathrm{~cm}^{-1}$. The peak at $1470 \mathrm{~cm}^{-1}$ corresponds to $\mathrm{C}-\mathrm{H}$ vibrations in semiquinone radical cation structure [33]. The peaks observed at $1531 \mathrm{~cm}^{-1}$ and $1624 \mathrm{~cm}^{-1}$, corre-
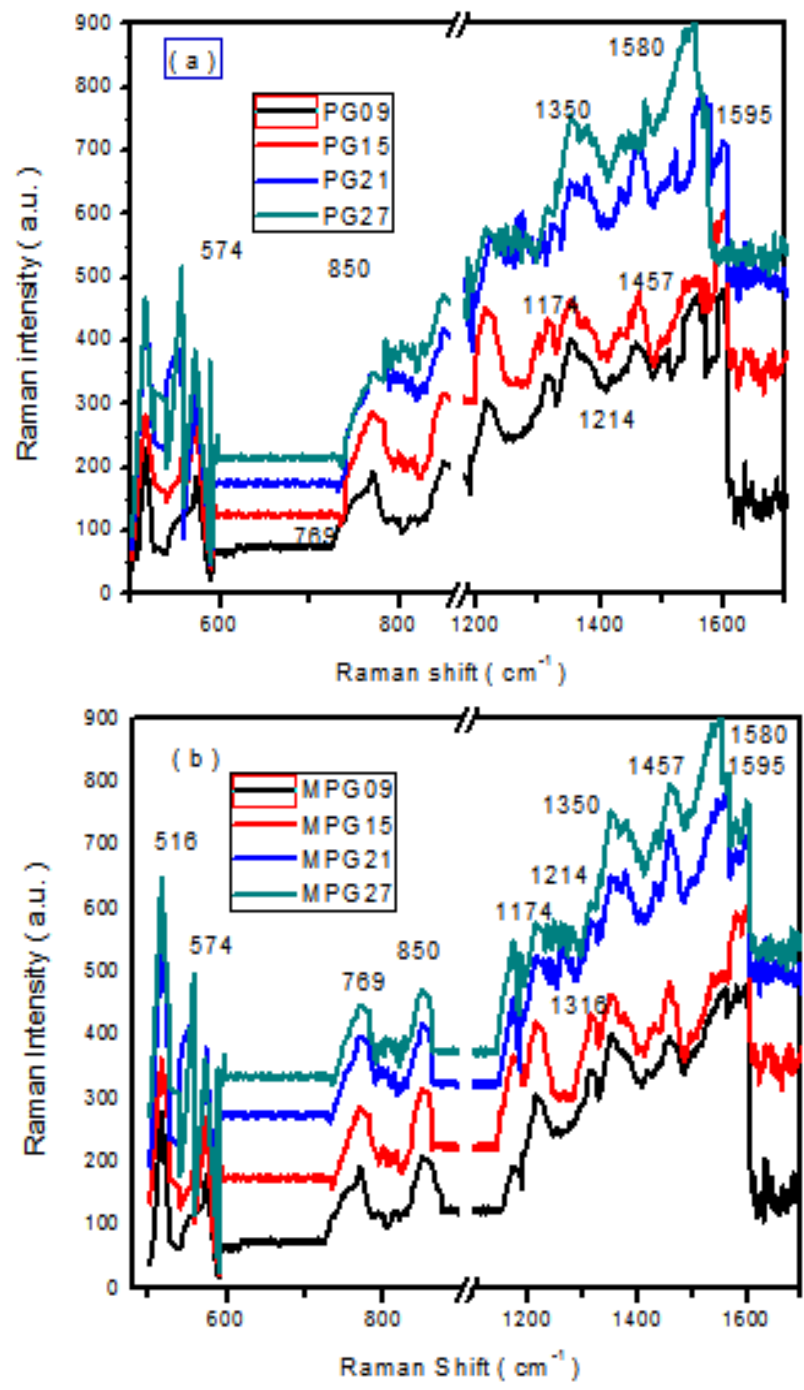

Fig. 2. Raman spectra of ( a ) graphene/polyaniline composite and ( b ) microwave treated graphene/polyaniline composite

sponding to $\mathrm{C}=\mathrm{C}$ stretching vibrations of the quinoid and benzenoid rings, respectively [27]. The peak at $1335 \mathrm{~cm}^{-1}$ for $\mathrm{C}^{-\mathrm{N}^{+}}$stretching of the bipolaron structure [29].

\subsection{Electrochemical measurement}

$\mathrm{CV}$ is considered to be a perfect tool to study and analyze the electrochemical performance of the samples with a potential window versus $\mathrm{Ag} / \mathrm{AgCl}$ at a scan rate of $10 \mathrm{mVs}^{-1}$, in $0.5 \mathrm{M} \mathrm{H}_{2} \mathrm{SO}_{4}$ solution. The electrochemical performance of graphene/polyaniline nanocomposite such as PG09, PG15, PG21, PG27 and microwave treated graphene/polyaniline nanocomposite MPG09, MPG15, MPG21 and MPG27 used as electrode materials for supercapacitors is evaluated by standard CV and GCD in a three electrode electrochemical workstation using $0.5 \mathrm{M} \mathrm{H}_{2} \mathrm{SO}_{4}$ electrolyte. A large current, rectangular type $\mathrm{CV}$ and symmetry in anodic and cathodic directions are the indications of the ideal capacitive behavior of the composite electrode materials [34]. Fig. 3 (a) and (b) illustrates the CV curve of all the prepared electrode material with a voltage range of -1.5 to $+2.0 \mathrm{~V}$ (scan rate, $10 \mathrm{mVs}^{-1}$ ). The CV forms of the PG09, PG15, PG21, PG27, MGP09, MGP15, MGP21 and MGP27 change tremendously with the increase of the mass ratios of GO/PANI. The CV curve of PG09, PG15, MPG09, MPG21and 

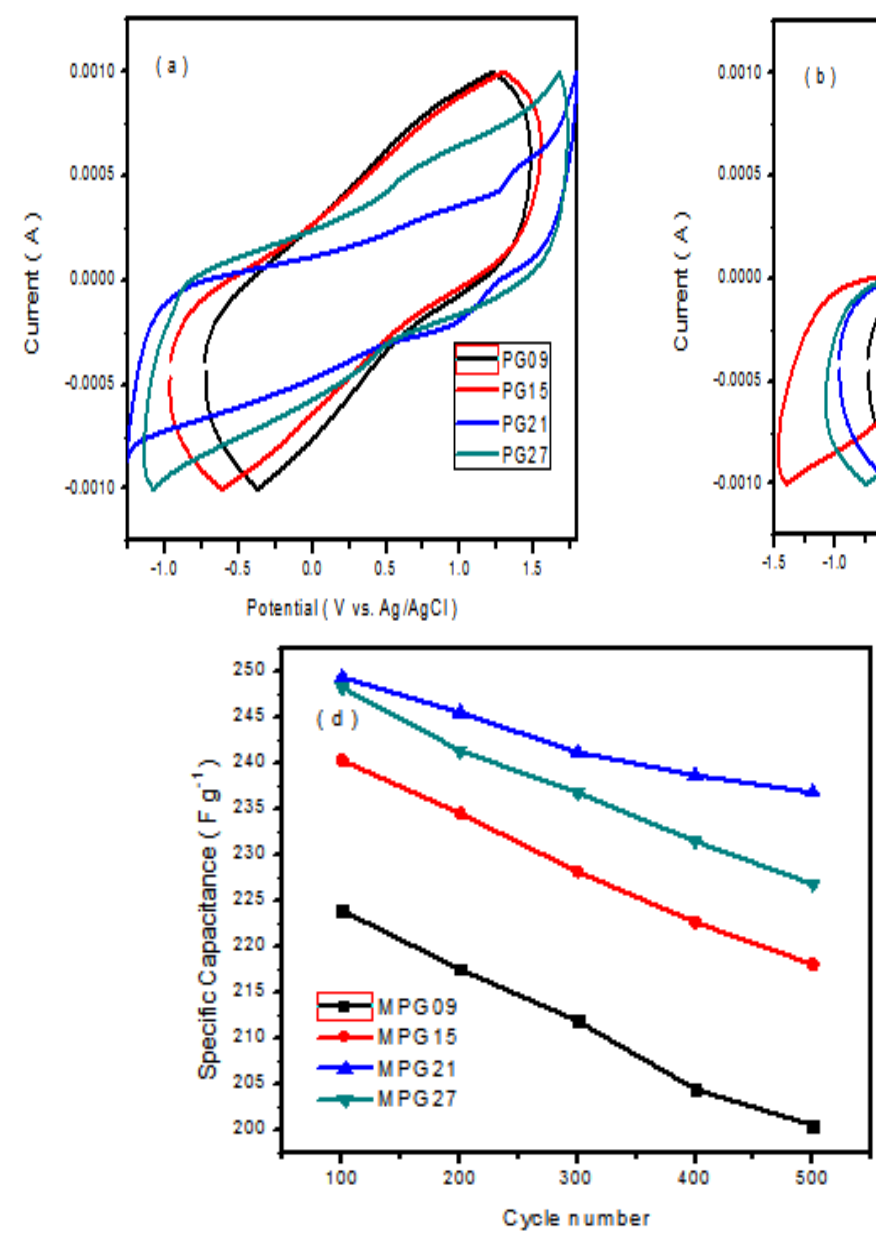
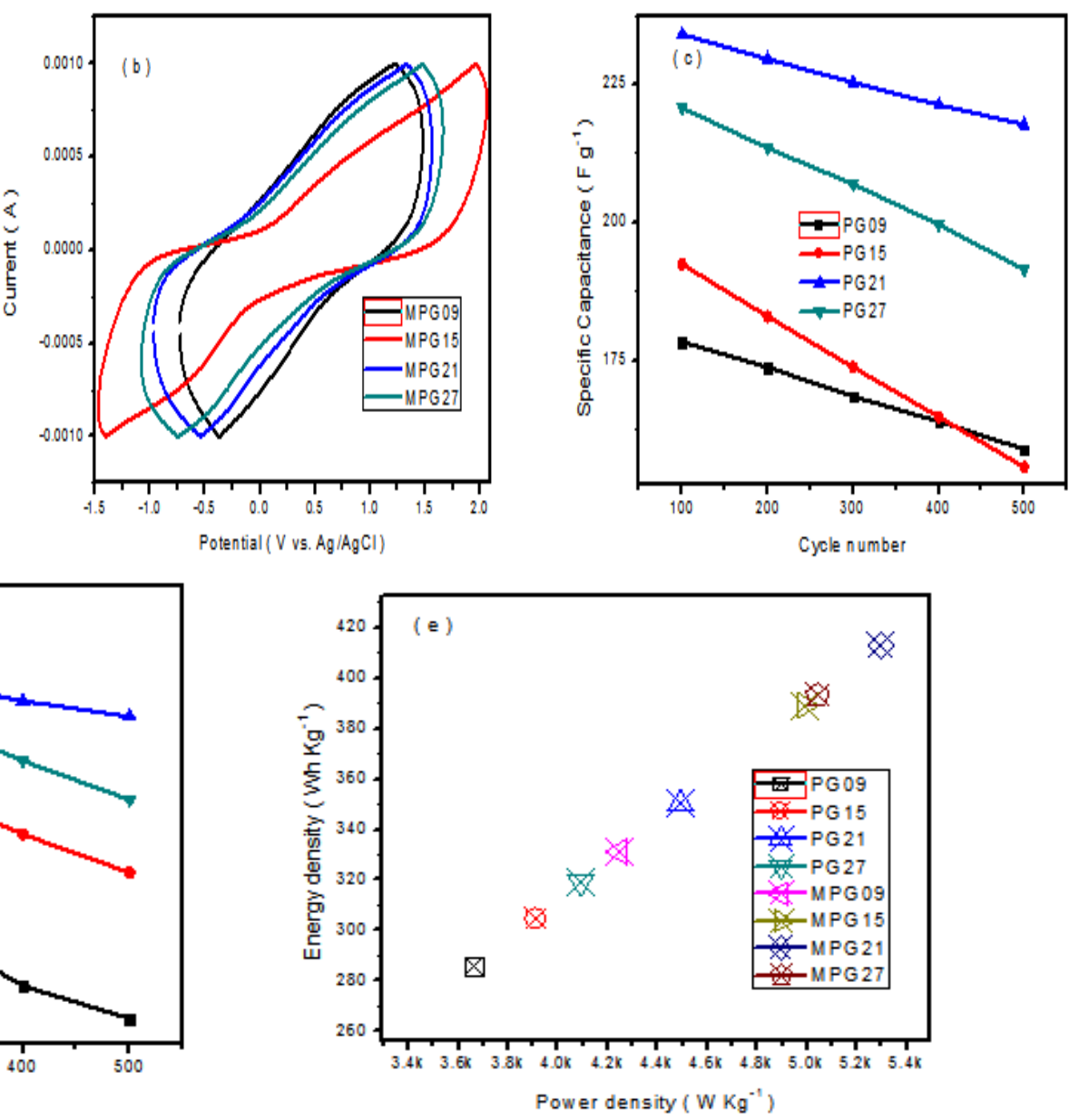

Fig. 3. (a) Cyclic voltammograms of graphene/polyaniline composite at scan rate $10 \mathrm{mVs}^{-1}$ in $0.5 \mathrm{M} \mathrm{H}_{2} \mathrm{SO}_{4}$ electrolyte and (b) Microwave treated graphene/polyaniline composite at scan rate $10 \mathrm{mVs}^{-1}$ in $0.5 \mathrm{M} \mathrm{H}_{2} \mathrm{SO}_{4}$ electrolyte, (c) Specific capacitance of graphene/polyaniline composites for various cycles at scan rate $10 \mathrm{mVs}^{-1}$ in $0.5 \mathrm{M} \mathrm{H}_{2} \mathrm{SO}_{4}$ electrolyte, (d) Specific capacitance of microwave treated graphene/polyaniline composite for various cycles at scan rate $10 \mathrm{mVs}^{-1}$ in $0.5 \mathrm{M} \mathrm{H}_{2} \mathrm{SO}_{4}$ electrolyte, (e) Ragone plot of graphene/polyaniline composite and Microwave treated graphene/polyaniline composite at scan rate $10 \mathrm{mVs}^{-1}$ in $0.5 \mathrm{M} \mathrm{H}_{2} \mathrm{SO}_{4}$ electrolyte

MPG27 is quasi rectangular in shape, representing EDLC behavior [9]. Evidently, the $\mathrm{CV}$ area of graphene/polyaniline composites indicating a higher specific capacitance of PG21 and the CV area of microwave treated graphene/polyaniline composites indicating a higher specific capacitance of MPG21. The capacitance calculated from the CV curve was mentioned by integrating over the $\mathrm{CV}$ curve to determine the average value of the area for one cycle [35]. It is important to note that the absolute area obtained from MPG21 is larger than other composite materials, at the same scan rate, suggested its higher specific capacitance.

Table 1. Specific capacitance, energy density and power density of graphene/polyaniline composite and microwave treated graphene/polyaniline composite

\begin{tabular}{|c|c|c|c|c|c|c|c|c|}
\hline & PG09 & PG15 & PG21 & PG27 & MPG09 & MPG15 & MPG21 & MPG27 \\
\hline Specific capacitance $\left(\mathrm{Fg}^{-1}\right)$ & 178.7 & 192.4 & 234.1 & 220.8 & 223.9 & 240.3 & 249.3 & 248.2 \\
\hline
\end{tabular}

Table 2. Specific capacitance of graphene/polyaniline composite and microwave treated graphene/polyaniline composite for 100, 200, 300,400 and 500 cycles

\begin{tabular}{|c|c|c|c|c|c|c|c|c|}
\hline $\begin{array}{c}\text { Cycles / Specific } \\
\text { Capacitance }\left(\mathrm{F} \mathrm{g}^{-1}\right)\end{array}$ & PG09 & PG15 & PG21 & PG27 & MPG09 & MPG15 & MPG21 & MPG27 \\
\hline 100 & 178.7 & 192.4 & 234.1 & 220.8 & 223.9 & 240.3 & 249.3 & 248.2 \\
\hline 200 & 173.8 & 183.0 & 229.7 & 213.5 & 217.5 & 234.5 & 245.5 & 241.3 \\
\hline 300 & 168.5 & 173.8 & 225.4 & 207.0 & 211.9 & 228.1 & 241.1 & 236.7 \\
\hline 400 & 163.9 & 164.8 & 221.3 & 199.7 & 204.5 & 222.7 & 238.6 & 231.5 \\
\hline 500 & 158.9 & 155.7 & 217.8 & 191.5 & 200.5 & 218.1 & 236.8 & 226.8 \\
\hline
\end{tabular}


The specific capacitance of the electrodes was calculated from the $\mathrm{CV}$ results according to the following equation (1-3).

$$
\text { Charge }=\frac{\text { Integrated area of } \mathrm{CV}}{2 * \text { Scan rate }}
$$

$$
\text { Capacitance }=\frac{\text { Charge }}{\text { Potential window }}
$$

$$
\text { Specific capacitance }\left(\mathrm{Fg}^{-1}\right)=\frac{\text { Capacitance }}{\text { Mass of active material }}
$$

The energy density and power density of the electrodes were calculated from the CV results according to the following equation (4-5).

$$
\begin{aligned}
& \text { Energy density }\left(\text { Wh } \mathrm{kg}^{-1}\right)= \\
& 0.5 * \text { Specific capacitance } * \text { potential window }
\end{aligned}
$$

$$
\text { Power density }\left(\mathrm{kW} \mathrm{kg}^{-1}\right)=\frac{\text { Energy density }}{\text { Discharge period }}
$$

From the Table 1, it is clearly observed that MPG21 has the highest specific capacitance among the composites. The electrochemical performances of the nanocomposite are enhanced due to the synergistic interaction between the PANI and the GO and the improved porous nature of microwave treated graphene/polyaniline composite. From the Table 2 MPG21 has the highest capacitance retention value than other composites. The cycling stability of the graphene/polyaniline and microwave treated graphene/polyaniline composite is given in Fig. 3 (c) and (d) at the scan rate of $10 \mathrm{mVs}^{-1}$. Graphene/polyaniline composite (PG09) losses $11.08 \%$ of its initial capacitance, after 500 charge and discharge cycles. However, only 7\% loss in the capacitance was noticed in the case of the composite PG21 under the same conditions. At the same time, same operating conditions microwave treated graphene/polyaniline losses $5 \%$ of its initial specific capacitance. The improvement in electrochemical stability may be attributed to the fact that porous nature of microwave treated composite provide more pathways and increases the charge transport mechanism. Ragone plot of graphene/polyaniline composite and Microwave treated graphene/polyaniline composite at scan rate $10 \mathrm{mVs}^{-1}$ in $0.5 \mathrm{M} \mathrm{H}_{2} \mathrm{SO}_{4}$ electrolyte is given in Fig. 3 (e). The highest energy and power density is opted for MPG21.

To further confirm the capacitive nature of graphene/polyaniline composite electrode, the electrochemical properties of graphene/polyaniline composite electrodes are fully tested by galvanostatic charge and discharge measurements in $0.5 \mathrm{M} \mathrm{H}_{2} \mathrm{SO}_{4}$ solution at a constant current density of $0.05 \mathrm{Ag}^{-1}$, within the potential range of -1.5 $\mathrm{V}$ to $+1.5 \mathrm{~V}$. Galvanostatic charge and discharge curves of the composite are demonstrated in Fig. 4 (a) and (b), in which each charge and discharge curve exhibits almost linear response, indicating general behavior of supercapacitors.

The specific capacitance is calculated, according to the following equation (6),

$$
\text { Specific capacitance }=\frac{(I X \Delta t)}{(m X \Delta V)}
$$
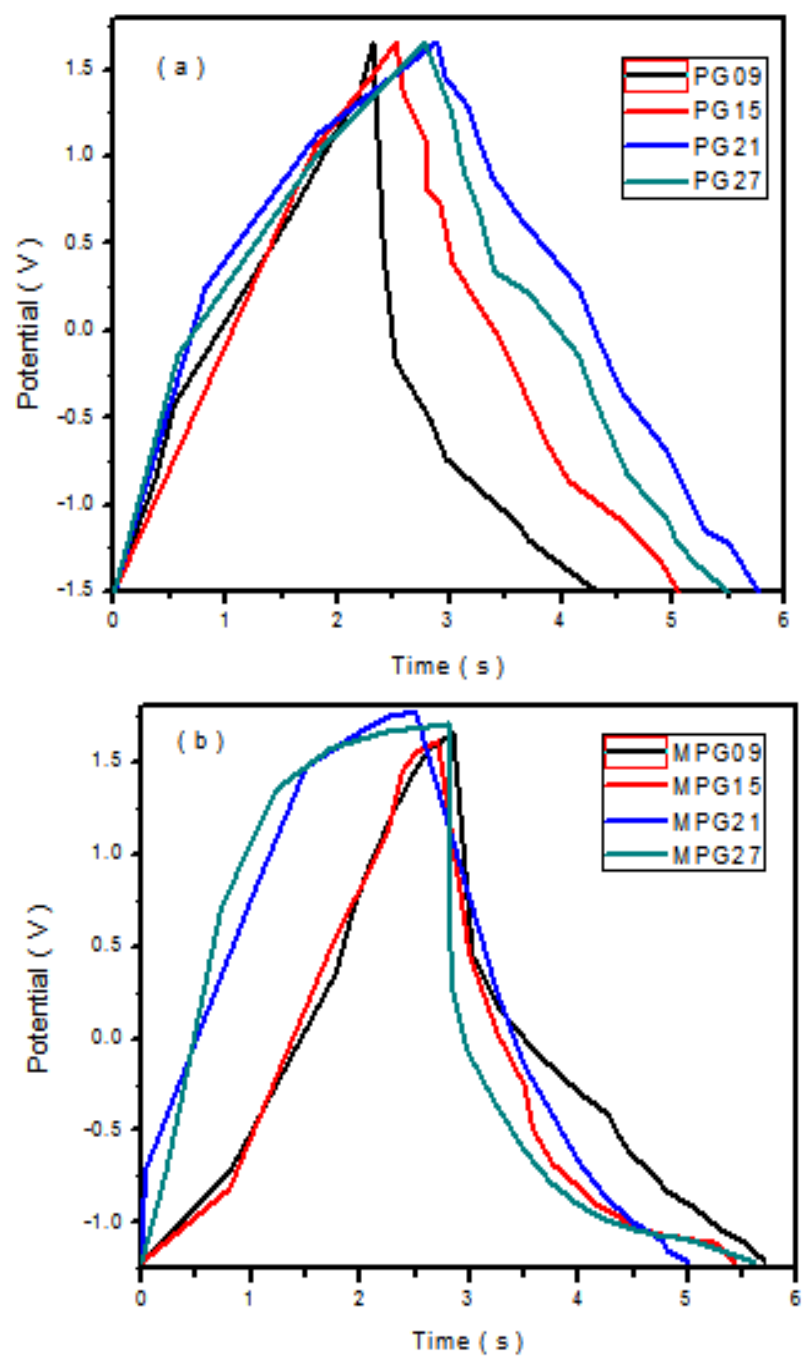

Fig. 4. Galvanostatic charge and discharge curves of (a) graphene/polyaniline composite and (b) microwave treated graphene/polyaniline composite

from the discharge curves.

$$
\text { Where, } \begin{aligned}
\mathrm{I} & =\text { charge/discharge current } \\
\Delta \mathrm{t} & =\text { discharge time } \\
\mathrm{m} & =\text { mass of electrode } \\
\Delta \mathrm{V} & =\text { potential window }
\end{aligned}
$$

\begin{tabular}{|c|c|c|c|c|c|c|c|c|}
\hline & PG09 & PG15 & PG21 & PG27 & MPG09 & MPG15 & MPG21 & MPG27 \\
\hline Specific capacitance $\left(\mathrm{Fg}^{-1}\right)$ & 180.7 & 207.7 & 244.4 & 217.0 & 210.4 & 248.8 & 256.2 & 249.8 \\
\hline Energy density ( $\mathrm{Wh} \mathrm{kg}^{-1}$ ) & 285.8 & 304.8 & 350.3 & 319.1 & 331.2 & 389.4 & 412.9 & 393.2 \\
\hline Power density $\left(\mathrm{W} \mathrm{kg}^{-1}\right)$ & 3664.3 & 3908.1 & 4491.1 & 4090.8 & 4246.2 & 4990.4 & 5293.9 & 5041.0 \\
\hline
\end{tabular}

The average specific capacitances are calculated to be $223.43 \mathrm{Fg}^{-1}$ for current density $0.05 \mathrm{Ag}^{-1}$, the values are consistent with the order indicated by the CVs.

A longer discharge time was observed in the composite (MPG21) compared to other combinations at the same current density meaning the high specific capacitance [32]. Table 3 summarizes the specific capacitances of the composite that are calculated from the charge- discharge curves. Therefore, the results reveal that the MPG21 composite

Table 3. Specific capacitance, energy density and power density of graphene/polyaniline composite and microwave treated graphene/polyaniline composite from GCD measurement. 

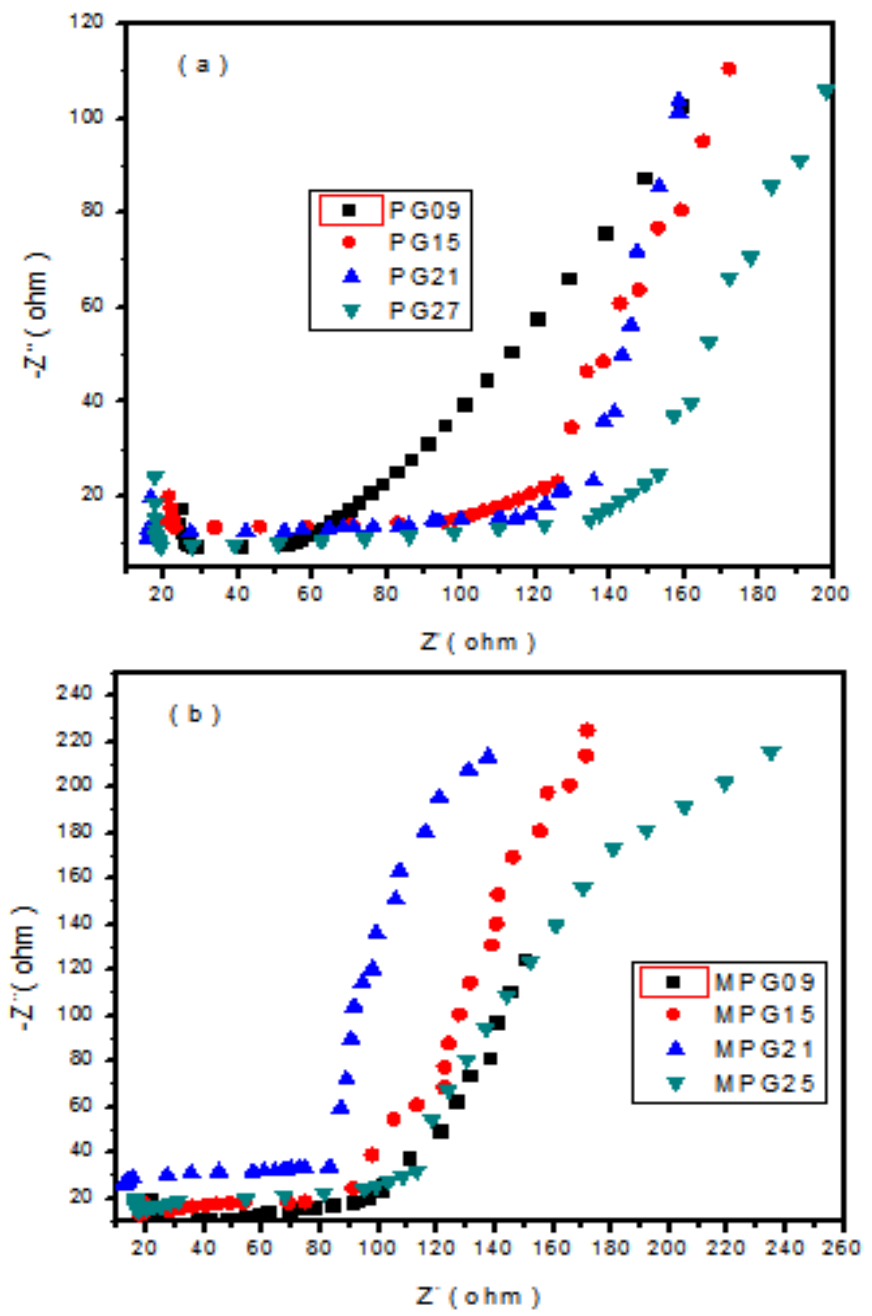

Fig. 5. Nyquist impedance plots of (a) graphene/polyaniline composite and (b) microwave treated graphene/polyaniline composite

with the high specific capacitance are most suitable for the high performance of electrochemical pseudocapacitance. IR drop of MPG21 is lowest among the other composites, reflects that the MPG21 possess minimum internal resistance.

The electrochemical properties of graphene/polyaniline composite and microwave treated graphene/polyaniline composite were further evaluated with electrochemical impedance spectroscopy with the frequency range of $0.1 \mathrm{~Hz}$. Electrochemical impedance spectroscopy is used to measure the bulk solution resistance ( including the electrolyte resistance, the collector/ electrode contact resistance and the electrode / electrolyte interface resistance ) and charge transfer resistance and ion diffusion processes of graphene/polyaniline composite and microwave treated graphene/polyaniline composite. Supercapacitors generally behave as pure resistors at high frequencies and capacitors at low frequencies. Theoretically, an ideal nyquist impedance plot features a semicircle over the high frequency region and a linear part in the low frequency range [14]. The low frequency region is mainly attributed to pure capacitive nature. The semicircular part and linear corresponding to electron transfer limited process and diffusion process, respectively. From Fig. 5, the almost vertical shape [ 14,24,27 ], representing the swift ion diffusion in electrolyte and the adsorption onto the electrode surface, suggests the ideal capacitive behavior of the MPG21 [ 13 ]. The observed larger semicircle for the composite electrode materials correspond to the higher charge transfer resistance which attributed to the poor conductivity of the composite electrode materials. At low frequency, the microwave treated composite electrodes exhibited a perfect vertical line than the composite electrode, showing an excellent capacitive behavior. Less ESR result in less voltage drop, less power loss and more efficiency, longer application time, more power, more current, less temperature rise and longer operational life time. The difference in charge transfer resistance can be attributed to the different electrical conductivities of electrode material. The charge transfer resistance of MPG21 is $0.1 \mathrm{Ohms}$, which is very less compared to other composite materials. The high electron transfer of MPG21 increases the electrical properties of redox process. The bulk solution resistance and charge transfer resistance of MPG21 attributed to good conductivity and porosity of the microwave treated composite.

\section{CONCLUSION}

In summary, we have synthesized the novel composites of graphene/polyaniline with different weight ratios through modified hummer's method and in situ polymerization for the development of supercapacitor, and proposed and demonstrated the microwave treatment of graphene/polyaniline nanocomposite to improve the porous nature and electronic conductivity of graphene/polyaniline composite. The mass ratio of graphene and polyaniline, and duration of microwave treatment of the composite is important for high electrochemical performance of the electrodes of the supercapacitor. The as prepared microwave treated composite were evaluated as electrode material for supercapacitor. The electrical conductivity and the specific capacitance of the graphene/polyaniline nanocomposites were improved due to the microwave treatment of graphene/polyaniline nanocomposites. The MPG21 has the highest specific capacitance of $249.32 \mathrm{Fg}^{-1}$ at $10 \mathrm{mVs}^{-1}$ and also shows good charge/discharge capability. The enhanced specific capacitance of microwave treatment composite electrode is attributed to not only the mixed effects of graphene and polyaniline but also the improved porous structure of microwave treated composite. The microwave treatment improves the porous nature of the composite, which further improve the charge transfer mechanism and ion transport through the electrodes. This high specific capacitance electrode material is a promising candidate for supercapacitor applications.

\section{REFERENCES}

[1] M. Beidaghi, Y. Gogotsi, Energy Environ. sci., 7, 867 (2014).

[2] H. Yang, J. Jiang, W. Zhou, L. Lai, L. Xi, Y. M. Lam, Z. Shen, B. Khezri, T. Yu, Nanoscale Res. Lett., 6, 1 (2011).

[3] J. Yan, Z. Fan, T. Wei, W. Qian, M. Zhang, F. Wei, Carbon, 48, 3825 (2010).

[4] Z. Wang, C. Ma, H. Wang, Z. Liu , Z. Hao, J. Alloys Compd., 552, 486 (2013).

[5] C. Xu, J. Sun, L. Gao, J. Mater. Chem., 21, 11253 (2011).

[6] S. Li, X. Lu, Y. Xue, J. Lei, T. Zheng, C. Wang, Plosone, 7, 1 (2012).

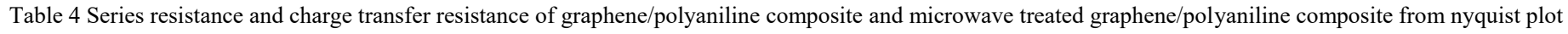

\begin{tabular}{|c|c|c|c|c|c|c|c|c|}
\hline & PG09 & PG15 & PG21 & PG27 & MPG09 & MPG15 & MPG21 & MPG27 \\
\hline Series resistance, $\mathrm{R}_{\mathrm{s}},(\Omega)$ & 23.8 & 20.9 & 15.3 & 17.4 & 20.4 & 18 & 12.7 & 16.4 \\
\hline Charge transfer Resistance, $\mathrm{R}_{\mathrm{ct}},(\Omega)$ & 4.9 & 2.0 & 1.3 & 1.7 & 3.7 & 1.7 & 0.5 & 1.0 \\
\hline
\end{tabular}


[7] P. A. Basnayaka, M. K. Ram, L. Stefanakos, A. Kumar, Graphene, 2, 81 (2013).

[8] A. Aphale, K. Maisuria, M. K. Mahapatra, A. Santiago, P. Singh, P. Patra, Sci. Rep., 5, 1 (2015).

[9] M. Liu, X. Wu, C. Chun, Q. wang, T. Wen, X. Wang, Sci. Adv. Mater., 5, 1686 (2013).

[10]Y. Xu , M. G. Schwab , A. J. Strudwick, I. Hennig ,X. Feng, Z. Wu, K. Mullen, Adv. Energy Mater., 3, 1035 (2013).

[11]H. Adelkhani, K. Didehban, R. Dehghan, Iranian J. Mater. Sci. Engg., 13, 29 (2016).

[12]C. Bora, J. Sharma, S. Dolui, J. Phys. Chem. C, 118, 29688 (2014).

[13]Z. Wang, X. Zhang, Y. Li, Z. Liu, Z. Hao, J. Mater. Chem. A, 1, 6393 (2013).

[14]G. Han, Y. Liu, L. Zhang, E. Kan, S. Zhang, J. Tang, W. Tang, Scientific. Rep. 4, 1 (2014).

[15]W. Lee, S. Suzuki, M. Miyayama, Nanomater., 4, 599 (2014).

[16]J. Kim, S. J. Park, S. Kim, Carbon Lett.,14, 51 (2013).

[17]M. B. Tayel, M. M. Soliman, M. E. Harb, Int. J. Adv. Res. in Electrical,Electron. \& Instrum., 4, 8064 (2015).

[18]H. Wang, Q. Hao , X. Yang, L. Lu, X. Wang, Electrochem. Coomun., 11, 1158 (2009).

[19]Y. Luo, D. Kong, Y. Ji, J. Luo, Y. Lu, D. Zhang, K. Qiu, C. Ming Li, T. Yu, Royal Soc. Chem., 3, 5851 (2013).

[20]V. H. Nguyen , C. Lamiel , D. Kharismadewi, V. C. Tran , J.J. Shim, J. Electroanalytical Chem., 758, 148 (2015).

[21]S.K.Kandasamy, K.Kandasamy, . J. Inorg. Organomet. Polym. 28, 559 (2018).

[22]Z. Tong, Y. Yang, J. Wang, J. Zhao, B.L. Su, Y. Li, J. Mater. Chem. A, 2, 4642 (2014).

[23]X. Li, H. Song, Y. Zhang, H. Wang, K. Du, H. Li, Y. Yuan, J. Huang, Int. J. Electrochem. Sci., 75163 (2012).

[24]F. Xiao, S. Yang, Z. Zhang, H. Liu, J. Xiao, L. Wan, J. Luo, S. Wang, Y. Liu, Sci. Rep., 5, 1 (2015).

[25]Z.S. Wu, X. Feng, H.M. Cheng, Nat. Sci. Review, 1, 277 (2014).

[26]K. K. Purushothaman, B. Saravanakumar, I. M. Babu, B. Sethuraman, G. Muralidharan, Royal Soc. Chem., 4, 23485 (2014).

[27]B. Rajagopalan, S. H. Hur, J. S. Chung, Nanoscale Res. Lett., 10, 1 (2015).

[28]X. Fan, Z. Yang, Z. Liu, Chin. J. Chem. 34, 107 (2016).

[29]Z. Wen, H. D.Wei, W. Y. Sheng, D. Xiang, X. Hao, Chin. Phys. B, 24,1 (2015).

[30]Y. Tang, X. Hu, D. Liu, D. Guo, J. Zhang, Polymers, 8, 1 (2016).

[31]H. Yang, N. Wang, Q. Xu, Z. Chen, Y. Ren, 2D mater., 1, 1 (2014).

[32]A.K. Sharma, P. Bhardwaj, S.K. Dhawan, Y. Sharma, Adv. Mater. Lett. 6, 414 (2015).

[33]D.W. Wang, F. Li, J. Zhao, W. Ren, Z.G. Chen, J. Tan, Z.S. Wu, I. Gentle, G. Q. Lu, H.M. Cheng, ACS Nano. 3, 1745 (2009).

[34]Y. Qian, S. Lu, F. Gao, J. Mater. Sci., 46, 3517 (2011).

[35]N.A. Kumar, H.J. Choi, Y.R. Shin, D.W. Chang, L. Dai, J.B. Baek, American Chem. Soc., 6, 1715 (2012). 